\title{
An Update on Traumatic Joint Dislocations in Nigeria
}

\author{
E. O. Edomwonyi ${ }^{*}$, R. E. T. Enemudo ${ }^{2}$ \\ ${ }^{1}$ Department of Orthopaedics and Traumatology, Irrua Specialist Teaching Hospital, Irrua, Nigeria \\ ${ }^{2}$ Department of Orthopaedics and Trauma, Delta State University Teaching Hospital, Oghara, Nigeria \\ Email: *edwinedomwonyi@rocketmail.com
}

Received 17 June 2015; accepted 27 July 2015; published 30 July 2015

Copyright (C) 2015 by authors and Scientific Research Publishing Inc.

This work is licensed under the Creative Commons Attribution International License (CC BY).

http://creativecommons.org/licenses/by/4.0/

(c) $($ i) 0 pen Access

\section{Abstract}

Trauma has assumed a pre-eminent epidemic proportion in the hierarchy of diseases afflicting the growing populace in Nigeria. Research into traumatic dislocations is relatively small. Road traffic accident is the commonest cause of traumatic dislocation in Nigeria currently. Human factors and collapse of road infrastructures are the major reasons. Young, productive, adult males are still the most affected while the rarity among children is again highlighted. Careful and detailed evaluation of patients is advised as certain conditions can mask the presence of a dislocation. Lack of diagnostic and therapeutic facilities in most centres in Nigeria makes this difficult, with clinicians resorting to clinical evaluation only and probably supported by only plain X-rays in some cases. Most cases are amenable to closed surgical management. Identification of long term complications is a major challenge, because of the poor follow up culture of our patients. Good road design and maintenance, enforcement of road regulations, manpower development and improvements in diagnostic and therapeutic facilities in all centres will reduce the burden of traumatic dislocations on the populace.

\section{Keywords}

Update, Traumatic, Dislocation, Nigeria

\section{Introduction}

The loss of anatomical congruence of bones in a joint or a complete disruption of a joint following trauma is referred to as traumatic dislocation. Articular surfaces are no longer in contact. In a healthy joint, the bones are held together by tough fibrous bands called ligaments. These ligaments are attached to each bone along a fibrous

${ }^{*}$ Corresponding author. 
sac surrounding the joint called articular capsule or joint capsule. These ligaments and joint capsule are relatively strong and non-elastic but permit movement within normal limits for a particular joint.

On application of excessive force, one or both bones in a joint could be forced out of its natural alignment through excessive stretching and tearing of the ligament(s) and capsule. Muscles and tendons surrounding the joint are stretched also. A traumatic dislocation occurs. When these disruptions and losses of articular alignment are incomplete, it is referred to as Subluxation. When a piece of bones forming part of the articular surface is sheared off, this makes fracture-dislocation.

Trauma and its related conditions represent a major epidemic of non-communicable disease in the present era. It is no longer considered accidental but is a part of the price we pay for technological progress. The burden of trauma worldwide is disproportionately concentrated in lower income countries like Nigeria. The world health organization anticipates that if current trends continue, road traffic injuries, interpersonal violence and self-inflicted injuries will all be among the leading 15 causes of durability—adjusted life years lost in the year 2020 [1].

Trauma is the leading cause of death and disability for people under 45 years in the industrialized world [2] [3]. These rates are declining in developed countries, but injuries are important and largely neglected health problem in developing countries [4] like Nigeria. Nigeria is the most populous country in Africa (population 140 million, National Census data 2006). Literature search for traumatic dislocations in Nigeria are surprisingly not many, paying attention to the hip joint alone in most cases. In Nigeria, changes that have been witnessed in some aspects of traumatic dislocations over the years are enumerated in this paper. Attitudes to trauma care and management, challenges that orthopaedic surgeons face in the evaluation and management of patients in Nigeria were also highlighted in this paper.

\section{Classifications}

Dislocations are classified based on anatomical distribution e.g. Shoulder, elbow, wrist, hip, knee etc. Each of these is further classified based on the direction of displacement of the distal of the articulating bones in the joint [5]. E.g.

A classification system is useful only if it helps to determine the proper treatment or predict the outcome. Each of the classification systems (Figure 1 and Figure 2 show classifications of dislocations involving the upper limb and lower limbs respectively) above aims to address these issues.

\section{Aetiopathogenesis}

Road traffic accident is currently the commonest cause of traumatic joint dislocations in Nigeria, with figures as high as 62\% - 95\% being recorded [7]-[10] Similarly high figures have been reported in India [11] as well as Saudi Arabia [12]. The hip joint is an inherently stable joint, requiring high velocity forces or energy to dislocate it; Posterior hip dislocation usually occur in a road accident when someone seated in a truck or car is thrown forward, striking the knee against the dashboard. Anterior hip dislocations may occur when a weight falls onto the back of a miner or building labourer who is working with his legs apart knees straight and back bent forwards, but nowadays [13] [14] the usual cause, is a road traffic accident or air crash-even a posteriorly directed force on an abducted and externally rotated hip may cause the neck to impinge on the acetabular rim and lever the femoral head out in front of its socket. Fracture-dislocations of the ankle are low energy injuries involving one or both malleoli, usually caused by a twisting mechanism.

Why do we have road injuries so high in Nigeria? Among the many obvious reasons of human factors is the collapse of road infrastructure as the main reason. Many of the roads were built before independence in 1960 and there are no alternative roads. The alternative means of travelling like air is erratic or as in railway is grounded. Waterways have not enjoyed sufficient attention as a desirable means of travelling. Bridges are narrow. Furthermore, some open lorries carry goods and passengers together such that after the crash, heavy goods fall on the victims.

Falls are low energy injuries that produce dislocations. A fall on the hand, the head of the humerus is driven forward, tearing the capsule and producing avulsion of the glenoid labrum (bankart lesion). This results in anterior dislocation of the shoulder. A fall on the outstretched hand with the outstretched hand with the elbow in extension disrupts the capsule and ligaments can result in posterior or posterior-lateral dislocation of the elbow joint. Older literatures on the incidence of traumatic joint dislocation in Nigeria, arising from falls were sparse, but currently less than 5\% has been reported [7]. Report [11] from India indicated 26\% which include falls from 

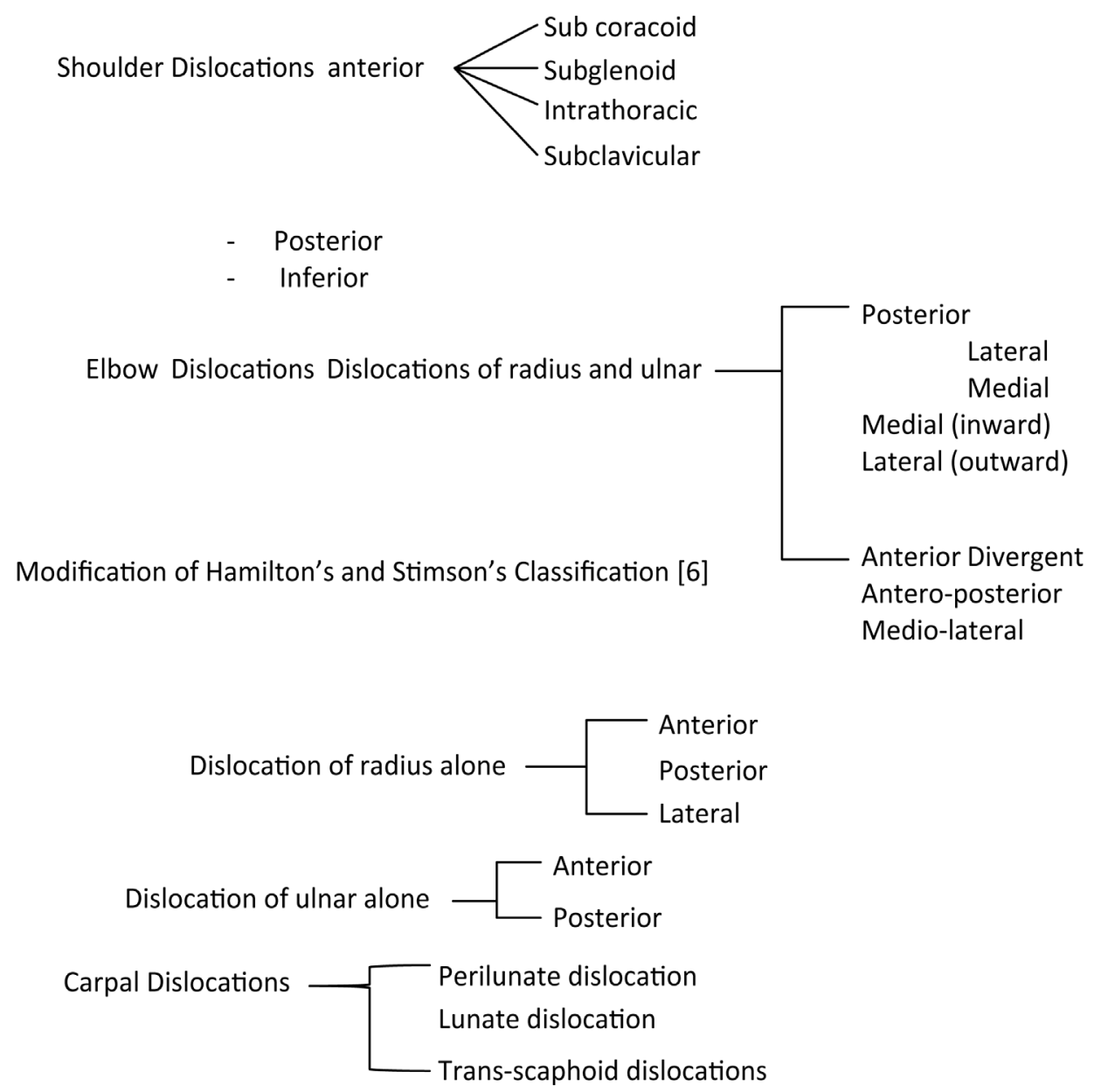

Figure 1. Classifications of dislocations involving the upper limb.

trees, high terrain or from roof of wooden houses in hilly areas while climbing wooden stairs. The following reasons may account for this. A reasonable number of patients that sustain trauma and orthopaedic injuries in Nigeria do notpresent early to the hospital, Injuries arising from falls are quite often closed or without open wounds and are considered "not serious", so they patronize traditional bone-setter's (TBS) homes, only to present in the our hospitals when complications they cannot cope with supervenes, such as sepsis, avascular necrosis (AVN) old nerve injuries occurs. These would attempt to explain the relatively low incidence of cases of traumatic joint dislocations presenting early to our hospitals in Nigeria currently. A fall with the hand forced into dosiflexion may tear the tough ligaments that normally bind the carpal bones resulting in dislocation of the wrist joint.

Collapsed mud house has been reported as a cause of joint dislocationin Nigeria accounting for 2\% [7].

Athletic injuries, assault, gun-shot, domestic violence are other uncommon causes in Nigeria. Fits or convulsions or electric shocks are also known causes of posterior dislocations of the shoulder joint.

\section{Epidemiology}

Previous reports [15] from Western Nigeria in the late $70 \mathrm{~s}$ showed a male preponderance in trauma and traumatic joint dislocation. In first decade of the $21^{\text {st }}$ century, reports [8] [16] [17] indicated a range of male to female ratio of 1.8:1 to as high as 4:1 from the Western and Eastern parts of Nigeria respectively. Current reports [7] [10] from Southern Nigeria showed a range of ratio of 7:1 to 7.6:1 in the last (second) decade of this century. This shows a consistency as well as an increase in the number of males affected. Males are often the bread winners in their families, making them more aggressive and vulnerable to automobile accidents which have been shown to be the commonest cause. 


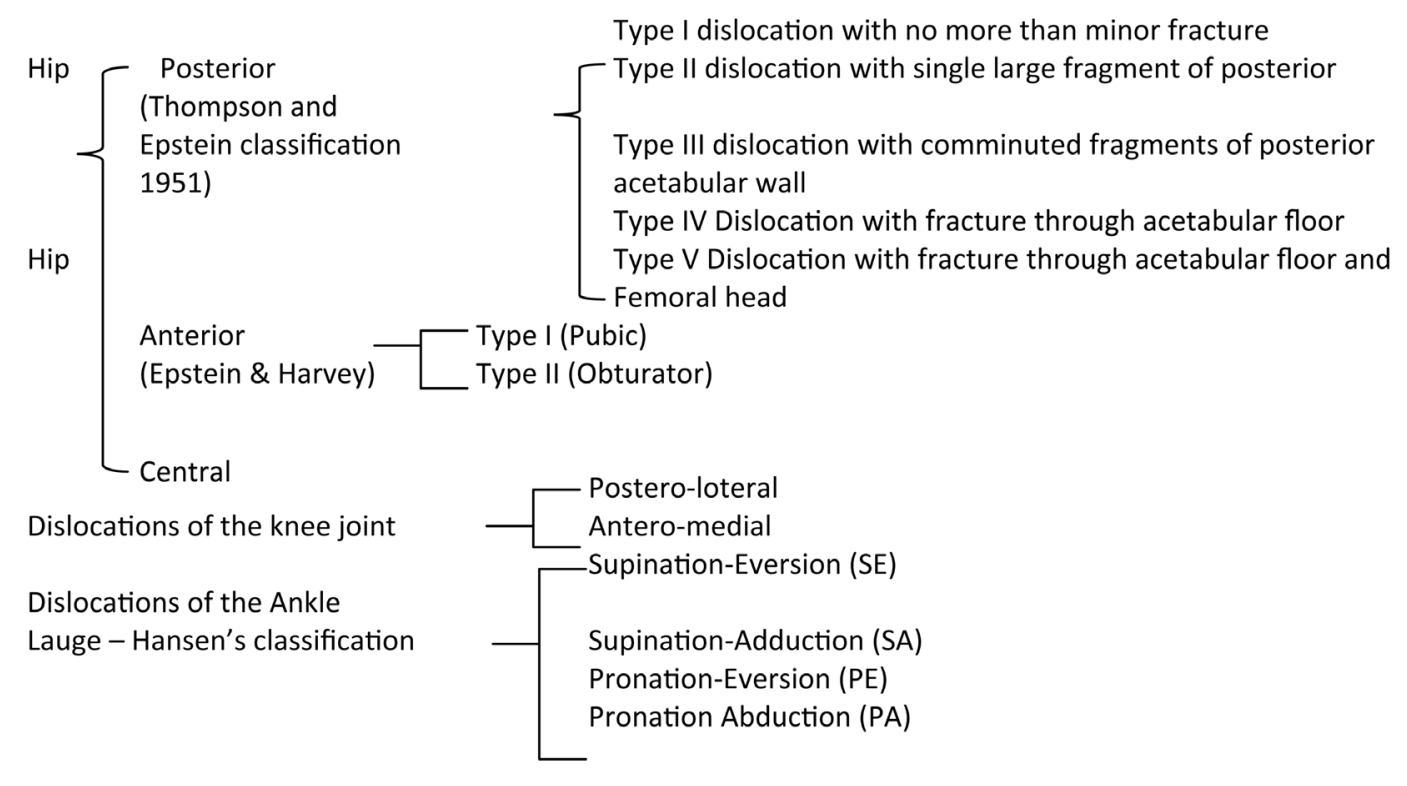

Figure 2. Showing classifications of dislocations involving lower limbs.

The young adults are the most affected. Mean age ranging from 30 - 34 years has been reported by various authors [7] [8] [10] [16] in Nigeria. These represents the most active, productive and mobile group. They are mainly workers involved in travels, transporting goods and services across the country. The vulnerability of the young adult male is consistent with findings [12] [18]-[20] from other parts of the world.

Dislocations are uncommon while fracture-dislocations are rare among children [21]. Ugbeye NE et al. [22] reported fracture-dislocation of the shoulder in a 7 year old girl. Few reports exist in literature, of such injury, in children less than 10 years of age [21] [23]. Traumatic hip dislocations in children have a bimodal distribution. The firstage group is 2 - 5 years of age owing to joint laxity and soft cartilage. The second age group is between 11 - 15 years of age owning to Athletic injuries and road traffic accidents.

Of the large joints, the shoulder is the one that most commonly dislocates. This is due to a number of factors the shallowness of the glenoid socket, the extraordinary range of movement, underlying conditions such as ligamentous laxity or glenoid dysplasia and the sheer vulnerability of the joint during stressful activities. Ebong [15] in 1978 reported shoulder dislocations as the commonest dislocations in Nigeria, followed by elbow dislocations. Meena et al. [11] in 2013 made a similar report in India, reporting 32\% for the shoulder $24 \%$ for the elbow, but Bhaskara et al. [18] reported the ankle joint as the most commonly dislocated joint reporting as high as 50\%. Enwelizu et al. [8] in 2008 and Edomwonyi et al. [7] in 2015 reported that the hip joint was the most commonly dislocated joint in Nigeria recording figures as $56 \%$.

Posterior type has been consistently reported as the commonest type of hip dislocation in Nigeria, with figures ranging 70\% - 96\% reported [7] [10] [15] [16] [24]. Grade l and lll constitute 75\% - 82\% of cases [7] [16] [24]. Type IV is the least common [10] [15]. The rarity of anterior dislocation has been maintained, authors [7] [8] reporting $6 \%-16 \%$. This is consistent with $12 \%$ reported by Epstein [25]. A bilateral anterior dislocation was reported [14] in Western Nigeria in 2005. This is extremely rare; those previously reported [26]-[30] cases were either bilateral posterior or a combination of anterior and posterior dislocations.

There is a disagreement in the literature regarding causative trauma and the side of the hip most commonly dislocated. Alonge et al. [16] and Edomwonyi et al. [10] reporting from Western and Southern parts of Nigeria respectively, reported right side involvement. Madu et al. reported left side involvement from the Eastern part of Nigeria, all in the last two decades. Levin et al. [31] reported that with left sided steering cars, the left hip was most vulnerable. Dreinhofer et al. [32] found no correlation with placement of the steering wheel.

Minimal research has been done on the other large joints in the body in Nigeria.

\section{Clinical Features}

Pain is severe. Swelling is of varied severity. In anterior shoulder dislocation, which is the commonest type of 
shoulder dislocation, the patient supports the arm with the opposite hand and refuses to permit any kind of examination. The lateral outline of the shoulder may be flattened; a bulge may be felt below the clavicle.

In posterior dislocation of the elbow, the patient supports forearm with the elbow in slight flexion. The deformity may be obvious; however in severe injuries pain and swelling are so marked that examination of the elbow is impossible.

Some cases are classical. Diagnosis is easy. The leg is short, lies adducted, internally rotated and slightly flexed as in the case of posterior dislocation of the hip joint. However, coma, fracture of the ipsilateral femur or tibia, dislocation or fracture of the contralateral hip could mask the presence of a hip dislocation [33] [34]. The golden rule is to $\mathrm{x}$-ray the pelvis in every case of severe hip injury, and with femoral fractures to insist on an $\mathrm{X}$-Ray that includes both the hip and knee. A thorough neurovascular assessment of the affected limb is usually advised, before any attempt at reduction.

\section{Investigations}

\section{Radiological}

Plain x-ray of various views, antero-posterior (AP), lateral and oblique view are very useful in the radiological evaluation of traumatic joint dislocations. This still the mainstay of diagnosis in most parts of Nigeria, particularly suburban and rural centres.

AP views of an anteriorly dislocated shoulder joint would reveal overlapping shadows of the humeral head and glenoid fossa, with the head usually below and medial to the socket. If the Joint had dislocated before, special views may show flattening or an excavation of the postero-lateral contour of the head, the Hill-Sach's lesion.

AP view of a posteriorly dislocated hip would reveal the femoral head displaced outside its socket and above the acetabulumas seen in Figure 3.

Beyond confirmation and classification of a dislocation, plain x-rays also helps to identify any associated fractures such as a segment of the acetabulum rim or femoral head, sheared off and displaced in posterior dislocation of the hip. An oblique view would be useful in demonstration of the size of the fragment which is helpful in its classification (see classification of hip dislocation (Thompson and Epstein). Computerized tomography (CT) scans in useful in fracture-dislocations.

CT scan is the best way of demonstrating an associated acetabular fracture (or any other bony fragment) [5]. Magnetic resonance imaging (MRI) studies are helpful in evaluating rotator cuff pathology associated with

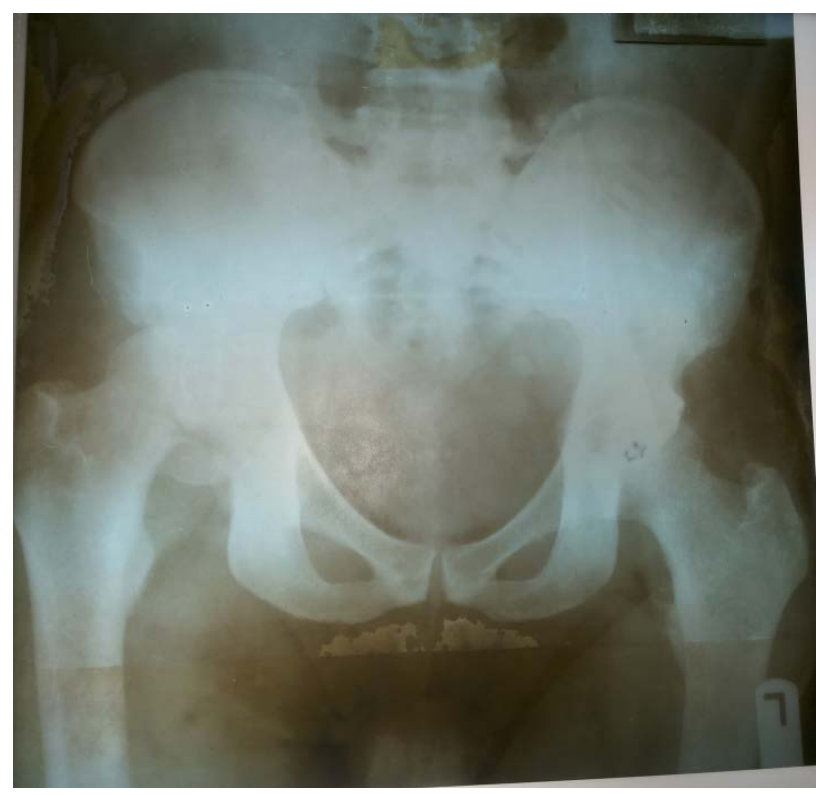

Figure 3. Posterior dislocation of the right Hip joint (pre-reduction). 
shoulder dislocations. It also helps to rule out osteochondral fragments, soft tissue inter-position which may contribute to irreducibility of the dislocation, MRI can effectively identify and quantify the muscle injury and Joint effusion that invariably accompany traumatic hip dislocations.

It is also useful for demonstrating trabecular bone contusion (trabecular Injury) and iliofemoral ligament injury, which occur commonly with acute hip dislocation [35].

Occasionally plain radiography or CT Scans can mis-judge the involvement of the posterior wall of the acetabulum in children due to the partially calcified nature of the paediatric bone. An MRI would identify an injury of this nature [36] [37]. A significant number of centres, particularly those in rural and suburban centres, including mine are yet to acquire equipments for CT scan and MRI studies. The impact, this major deficiency, has on our diagnostic capacity is better imagined.

\section{Treatment}

After diagnosis has been established, they should be treated as emergencies. Treatment is directed toward avoiding complications by prompt reduction of the dislocations and providing congruent and stable joints [38] [39]. Pathological changes occur, especially about the hip. However, immediate reduction of an acute dislocation does not guarantee a satisfactory result [39] and the patient should be informed of this at the time of the initial evaluation and treatment. A careful neurovascular assessment should be done and carefully recorded on the patient's chart before reduction is performed.

The time interval between injury and reduction should be less than 6 hrs, particularly for dislocations of the hip. In the past, it was noted that patients present late to the hospital in Nigeria, primarily because of transportation challenges, rough terrain, shortage of equipped hospitals and facilities in the rural and suburban areas.

Reports in the decade of this century revealed that, as much as $72 \%$ of patients presented and had reduction of dislocations done in less than 12 hrs. Reports [7] Southern Nigeria showed a more impressive turnout, 76\% of patients presented and had reduction of dislocationsin less than 6 hours. Increase in awareness, availability of trained manpower and facilities in these parts of the Nigeria, severe pain and anxiety that follow acute injury cause patients to present early are identifiable reasons for this encouraging turnout. Motorcycle is the mainstay means of transportation in Nigeria, particularly in rural and suburban areas. They are accessible, readily available and can ride across terrains that are difficult or almost impossible to cars. Members of most communities form a closed niche, playing the role of Good Samaritan to each other. Following an injury, a motorcycle rider is easily and readily mobilised, hence they quickly bring them to the hospital. Reports [20] from Brazil indicated that $37 \%$ of patients presented and had their dislocations reduced in less than 6 hrs, while 32.5\% between 6 hours to 12 hours.

Closed reduction with intravenous analgesia and sedation or with general anaesthesia should be attempted first for most uncomplicated dislocations. When general anaesthesia is necessary, operating room personnel should prepared for the possibility of an open procedure if closed reduction is unsuccessful.

The key to reduction of any dislocation is muscle relaxation under general anaesthesia; most dislocations reduce with remarkable ease. In the early part of this century, most dislocations in Nigeria were reduced by close manipulation following the administration of intravenous analgesics and diazepam as opposed to general anaesthesia [16]. This management was adopted because of the delay in securing theatre spaces, dearth of anaesthestists and reluctance of Nigerian patients to accept general anaesthesia. Current reports reveal the opposite as these constraints are much less pronounced today [7].

Reduction techniques have been categorized as traction, leverage, or rotational techniques. It is likely that, in most cases, all are involved in some degree, because there is considerable overlap and modifications of methods. Stimson's technique, Hippocratic and Kocher's methods are various techniques that have been used to reduce anterior dislocation of the shoulder joint. Kocher's method is capable of reducing most dislocations without difficulty. It is characterized in succession by traction, abduction and external rotation, followed by adduction and internal rotation. Excessive or forceful leverage should be avoided to prevent additional soft tissue damage or fracture of the humeral neck. Some authors [5] have opined that this technique carries the risk of nerve, blood vessel and bone injury and hence it is not recommended. Experience in my centre, strongly support the adoption of the Kocher's manoeuvre as we have not had any of the reported untoward complications in nearly a decade of our practice.

Reduction of dislocated hip requires general anaesthesia and adequate muscle relaxation, because of the bulky 
nature of the muscles involved. In vast majority, Watson-Jones Manoeuvre is adopted. If this is not achieved after two or three attempts, an open reduction is required. An assistant steadies the pelvis; the surgeon starts by applying traction in the line of the femoral shaft as if lies (usually in adduction and internal rotation) and then gradually flexes the patient's hip and knee to 90 degrees, maintaining traction throughout. At 90 degrees of hip flexion, traction is steadily increased and sometimes a little rotation (either internal or external) is required to accomplish reduction. A satisfying "clunk" terminates the manoeuvre. Assess the stability of the reduced hip by flexing the hip to 90 degrees and applying a longitudinal and posteriorly directed force, screening the hip for signs of Subluxation, evidence of which should prompt repair of the posterior wall of the acetabulum. X-ray or CT scan is taken to confirm reduction and exclude a fracture. Please see Figure 3 showing a plain radiograph of a dislocated right hip joint and Figure 4 shows a satisfactory reduction of the same joint following closed manipulation. A neurological assessment is done when patient is awake. As for the shoulder, when the patient is fully awake, active abduction is gently tested to exclude an axillary nerve injury and rotator cuff tear. The median, radial, ulnar and musculo-cutaneous nerves are also tested and the pulses are felt.

Arm is rested in a sling for about 3 weeks. Throughout this period, elbow and finger movements are practised daily. Amenability for most traumatic dislocations to get successfully reduced by closed manipulation is the situation in Nigeria. Authors [7]-[9] have reported 93\% - 96\% success in different parts of Nigeria.

Delay in reduction of acute dislocations ( $>24 \mathrm{hrs}$ ) was present in $11.63 \%$ in our series [7] and $18.8 \%$ was reported [16] from western Nigeria. These were due to late presentations. The delay could have been avoided if the diagnosis were promptly made by the attending physician and reduction or referral made immediately.

Following closed reduction, immobilisation of the joint is important. This is to enable healing of the injured soft tissues. As for the hip the period of "protection" varies according to the risk of avascular necrosis. If the reduction was performed prompt ( $<6 \mathrm{hrs}$ ), immobilization by skin traction for less than 6 weeks would be adequate. If there was a longer delay then an extended period of 12 weeks is advised [5]. Progression of weight bearing should be graduated and the hip Joint monitored by X-ray or CT scan. Occasionally closed reduction fails after multiple attempts. If reduction is not achieved in a dislocated hip after 2 or 3 attempts, an open reduction is required [5].

Indications for open reduction include but not limited to the following:

1) If anatomical, concentric reduction cannot be achieved by gentle, closed techniques with the patient under general anaesthesia, interposed soft tissues or osteochondral fragments, may contribute to the irreducibility.

2) If a stable reduction cannot be maintained. Articular fractures often are unstable and must be reduced and fixed to insure stability of the reduction.

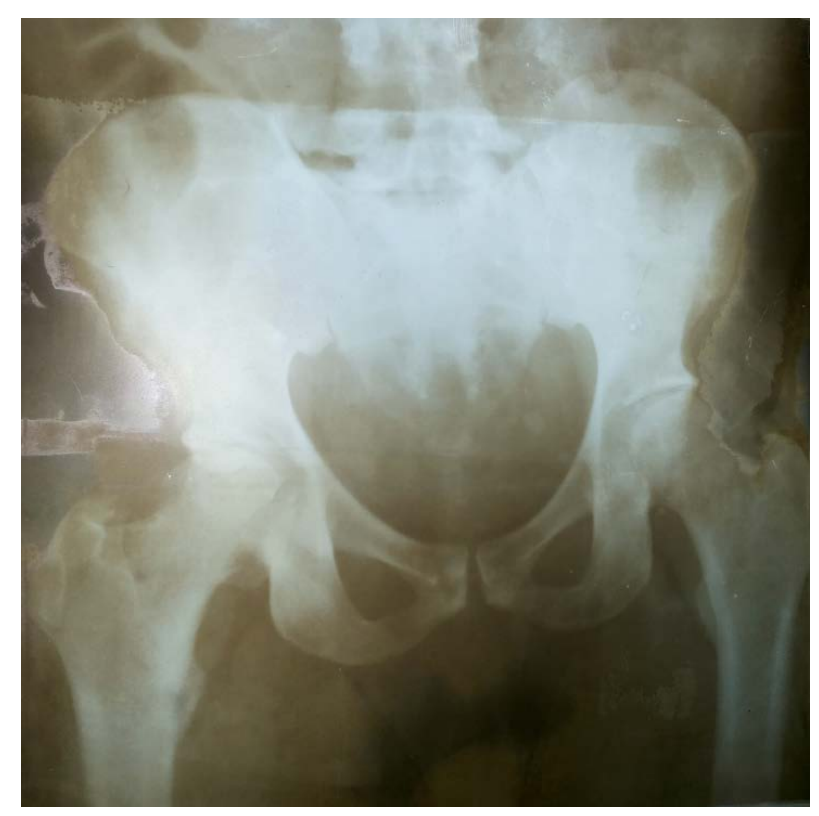

Figure 4. Posterior dislocation of the right hip Joint (postreduction). 
3) If careful evaluation before closed reduction reveals normal neurological function and after reduction a definite, complete motor and sensory nerve deficit becomes evident.

4) If circulatory impairment distal to the artery is well documented before reduction and persists after reduction. Further assessment of the circulation is essential and should include arteriography.

5) If ischemia is persistent, surgical exploration with appropriate management of the vascular injury is indicated.

Our experience [7] indicate that cases requiring open reduction were hip dislocations, apparently because of the bulky size of the muscles involved in spasm.

Following open reduction, anatomical fixation of detached fragment if significant, interposed soft tissues are removed; small or minor fragments are washed off during joint irrigation. Neurovascular impairment if any is appropriately addressed. The dearth of vascular surgeons in Nigeria has made this a major challenge. In most centres, like ours, cardio-thoracic surgeons who have some experience in vascular surgeries attempt to address some these problems. This, of course has its limits. The absence of very important diagnostic, operating tools and trained manpower in most centres in Nigeria such C-arm fluoroscopy makes operative fixation of pelvic injuries associated with hip dislocation difficult. These facilities when present in some centres are poorly maintained, manpower is not regularly updated and this takes its toll on service delivery. Very few centres that have these facilities are located in urban centres, with charges out of the reach of the vast majority.

Follow-up of patients in most series [7] [16] in Nigeria has consistently reported poor results. A significant number of patients even discharge themselves against medical advice while still on admission. After closed manipulation, joint is immobilized, patient generally feel nothing is being done any more, since pain had abated. Some of these patients go to traditional bone-setter's (TBS) home. TBS have an appeal to the citizenry in Nigeria for reasons bothering on cheap cost, alleged and false perception of faster healing and care [40] or weak personal decision making skills [41].

Following discharge majority of patients do not even turn up after first visit at the surgical outpatient clinic.

Alonge et al. [16] reported that no patient attended the outpatient clinic after six months following discharge. Our experience in this centre is not different. Incidence of long-term complication of acute traumatic dislocations would be difficult to ascertain in our patients because of the dropout rate from poor follow-up.

\section{Complications}

\subsection{Early}

\subsubsection{Associated Injuries}

Considering the enormity of the force required to cause dislocations of the hip, an inherently stable joint, associated injuries occurring, would not be a surprise. Figures as high as $45 \%-77 \%$ had been reported by various authors [7] [9] [10] in Nigeria. 74.4\% was reported in Brazil [19]. A Japanese review of traumatic dislocations of the hip in children found that $<5 \%$ of hip dislocations were associated with femoral fractures [42].

Edomwonyi et al. [7] reported long bone fractures, as the most common associated injury while same authors [10] but in another study involving only hip dislocations revealed acetabular fractures. This was corroborated by Alonge et al. [16]. Enweluzo et al. [8] reported Head injuries as commonest associated injury in a separate report from the Eastern part of Nigeria. The Brazilian study [21] working on hip dislocations alone in children reported hip fractures.

33 children with traumatic hip dislocations were reviewed in Toronto, Canada. Associated injuries were seen in 10 patients but none had associated hip fractures. Associated fracture of the proximal humerus could complicate anterior dislocation of the shoulder joint. The greater tuberosity may be sheared off. It usually falls into place during reduction, if it remains displaced, surgical re-attachment is recommended. Open reduction and internal fixation may necessary in other cases of associated fractures. Internal fixation and reconstruction of posterior acetabular wall is a surgery that would require trained manpower, modern facilities like C-arm fluoroscopy and other technical skills. These are still a luxury in most centres in Nigeria at present, particularly those located in rural and suburban centres like ours. Patients end up being stabilized and referred to those few centres with such facilities. The rigors of travelling and cost, discourages most patients particularly the poor who constitute the majority of the patients in our vicinity. Some eventually seek the services of TBS.

\subsubsection{Nerve Injury}

Nerve injuries occur following acute dislocations. Radial nerve, musculocutaneous nerve, median nerve, ulnar 
nerve, axillary nerves may be damaged in shoulder dislocations, rarely there is complete infraclavicular brachial plexus palsy. Sciatic nerve may be involved in hip dislocations, while median and ulnar nerves in elbow dislocations.

Sciatic nerve and axillary nerve are particularly at risk in hip and shoulder dislocations respectively. $0 \%-10 \%$ sciatic nerve injury were reported by authors [7] [9] from the South and Eastern part of Nigeria. Literature [36] recorded $10 \%-20 \%$ of cases associated with hip dislocations. Median and ulnar nerves may be injuredoccasionally in elbow dislocations.

Nerve function must be tested and documented before reduction is attempted. If, after reducing the dislocation, a sciatic nerve lesion is diagnosed, the nerve should be explored to ensure it is not trapped by the reduction manoeuvre. Recovery of the sciatic nerve injury takes months, while the ankle is splinted to overcome foot drop.

Axillary nerve lesion is usually a neurapraxia which recovers spontaneously after a few weeks. If it does not, then surgery, should be considered as the results of repair are less satisfactory if the delay is more than a few months.

\subsubsection{Vascular Injury}

Vascular injury is rare. A high index of suspicion is required as less obvious injuries associated may occur particularly that affecting the intimal of the blood vessels. To the best of the author's knowledge, there is no report of vascular injury complicating joint dislocation injury in Nigeria currently. Axillary artery may be damaged particularly in the aged with fragile vessels. This can occur either at the time of injury or during overzealous reduction. Brachial artery is at risk in elbow dislocation. Absence of radial pulse is a warning. This should be treated as an emergency. Splints are removed, elbow straightened, if there is no improvement an arteriogram is performed and the brachial artery explored.

Occasionally the superior gluteal artery may be torn in hip dislocations, bleeding may be profuse. It is managed like in brachial artery injury.

\subsubsection{Rotator Cuff Tear}

This may follow shoulder dislocations, particularly in the older people. Most do not require surgical attention, but young and active individuals with large tears will benefit from early repair.

\subsection{Late}

\subsubsection{Avascular Necrosis}

(AVN)Avascular necrosis of the femoral head has been reported [35] in about 4\% - 22\% of traumatic hip dislocations in Nigeria. If reduction is delayed $<12 \mathrm{hrs}$, the figure rises to $40 \%$ [5]. It is related to the severity of trauma and time of reduction.

Ischemia is due to interruption of femoral head blood supply when the hip is dislocated. This is due to compression, traction or arterial spasm.

Reports from Nigeria [7] [9] [10] revealed figures as low as $4 \%$. Reason is not because this is truly low, but for the following reasons:

a) MRI and Isotope bones scan machines, that should detect early changes are not readily available, where available, they are inaccessible or unaffordable.

b) X-ray (which is the most readily available investigative or follow-up tool) may not reveal the typical increased bone density pattern associated with AVN until at least 6 weeks after trauma, and sometimes very much later (up to 2 yrs) depending on the rate of repair. Patients in our environment have a very poor follow-up culture. Majority of our patients do not turn up after $1^{\text {st }}$ visit at the surgical outpatient department [7]. Cases where no patient presented for follow up six months after discharge from hospital had been documented [16] [18]. This make incidence of AVN appear, low or difficult to accurately determine in Nigeria.

If necrotic segment is small re-alignment Osteotomy is the method of choice, for extensive femoral head collapse, joint replacement is advised.

The prevalence of AVN complicating traumatic hip dislocations among children in Nigeria is sparse. Reports from developed countries are available. The largest published series is a multicentre study from the Scientific Research Committee of the Pennsylvania Orthopaedic Society. They reviewed 165 patients with dislocated hips. They found $10 \%$ incidence of AVN, which was associated with a delay in reduction (>24 hrs) or severe trauma. 
33 children with traumatic hip dislocation were reviewed from Toronto, Canada; only one child developed AVN (3\%).

\subsubsection{Degenerative Joint Disease}

This is due to cartilage damage, presence of retained fragments in the joint and Ischaemic necrosis of the femoral head. Dreinhofer et al. [32] reported an incidence of $26 \%$.

Reports [9] from Eastern Nigeria revealed $4 \%$ but for poor follow-up culture, this is difficult to estimate among Nigerians.

\subsubsection{Joint Stiffness}

Loss of 20 - 30 degrees of extension is not uncommon after elbow joint dislocation. Fortunately this is usually of little functional significance. This is due to prolonged immobilization. Elbow should be moved as soon as possible with due consideration to stability of the fractures and soft tissues and without undue passive stretching of the soft tissues.

Prolonged Immobilization may lead to stiffness of the shoulder, especially in patients over the age of 40 yrs. Active exercise will usually loosen the joint. Manipulation under anaesthesia or arthroscopic capsular release is advised only if progress halts and at least 6 months have elapsed since injury.

\subsubsection{Unreduced Dislocations}

Some patients present late in Nigeria. This may be due to delays in transportation, to the relatively few well equipped centres, delay in diagnosis due to attendance by non-trained personnel in secondary centres, associated injuries that demand priority in emergency cases, and some presented after staying for weeks or even months at the TBS homes.

Reports [7] [9] [10] [16] from various parts of Nigeria reported $11 \%$ - 25\% of patients presenting $>24$ hrs after trauma, which is considered to be delayed. The incidence of stiffness and AVN is increased and if established in patients with hip dislocations, they would need reconstructive surgery.

Dislocations of the shoulder occasionally is missed, if patient is either unconscious or very old [5] closed reduction is worth attempting up to 6weeks after injury. Manipulation later may cause fracture or tear blood vessels or nerves. Operative reduction is indicated after 6 weeks only in the young. Anterior approach is advised.

\section{Recurrent Dislocation}

Detachment of the glenoid labrum or the capsule is stripped off the front of the neck of the glenoid leading to recurrence of anterior dislocation of the shoulder. This should be repaired, Bankart procedure or anterior capsule shortened, putti-platt procedure (not commonly done these days).

\section{Prognosis}

Outcome is dependent on many variables [43] [44] such as cartilage damage on impact and injury to the blood supply to one or more parts of the articulating bones, femoral head for example, extent of associated injuries are beyond the control of the surgeon. Others are timing and accuracy of the reductionsare variables that can be positively influenced by recognizing and treating dislocations as emergencies. Axillary nerve palsy complicating a shoulder dislocation after 10 weeks carries a poor prognosis [45].

\section{Conclusions}

Young, active and productive adults have been identified as the group of patients involved in traumatic dislocations in Nigeria currently. Road traffic accident is the commonest cause. Better road design and maintenance, enforcement of road regulations such as avoidance of over-speeding, drunk driving, insistence on high standard of vehicle maintenance will reduce the incidence of road traffic accidents.

Enlightenment of the populace, on the need to present to the hospital early, punctuality with clinic visits should be emphasised.

Provision of ambulances at strategic locations, manpower development, training and re-training, provision of infrastructures, diagnostics and therapeutic facilities like CT scan and MRI in all rural and suburban centres will 
improve capacity to evaluate and manage our patients.

\section{References}

[1] Detels, R., Beaglehele, R., Lang sang, M.A. and Gultiford, M. (2009) Oxford Textbook of Public Health. 5th Edition, Oxford University Press, New York. http://dx.doi.org/10.1093/med/9780199218707.001.0001

[2] Zwi, A. (1993) The Public Burden of Injury in Developing Countries a Critical Review of Literature. Trop. Dis. Bull, 90, 5-45

[3] Forjouh, S.N. and Gyebi-Ofosu, E. (1993) Injury Surveillance: Should It Be Concern to Developing Countries? Journal of Public Health Policy, 14, 355-359.

[4] Onotade, F.J., Fatusi, O.A. and Ojo, M.A. (2004) Call Hour Maxillofacial Emergencies Presenting to a Nigerian Teaching Hospital. African Journal of Oral Health, 1, 17-24.

[5] Solomon, L., Warwick, D. and Nayagam, S. (2010) Injuries of the Hip and Femur. In: Solomon, L., Warwick, D. and Nayagam, S., Eds., Apley's System of Orthopaedics and Fractures, Chap. 29, 9th Edition, CRC Press, Boca Raton, 740-845. http://dx.doi.org/10.1201/b13422-33

[6] Chapman, M.W., Bray, J.J., Spiegel, P.G. and Green, S.A. Traumatic Dislocation of the Shoulder Girdle and Elbow. In: Michael, W.C., Operative Orthopaedics, Vol. 1, 2nd Edition, Lippincott Company, Philadephia, 472.

[7] Edomwonyi, E.O., Nwokike, O.C. and Onuminya, J.E. (2015) Management of Traumatic Joint Dislocations in Irrua. Surgical Science, 6, 116-122. http://dx.doi.org/10.4236/ss.2015.63018

[8] Enweluzo, G.O., Giwa, S.O. and Obalum, D.C. (2008) Pattern of Extremity Injuries in Polytrauma in Lagos, Nigeria. The Nigerian Postgraduate Medical Journal, 15, 6-9.

[9] Onyemaechi, N.O. and Eyichukwu, G.O. (2011) Traumatic Hip Joint Dislocations at a Regional Trauma Centre in Nigeria. Nigerian Journal of Medicine, 20, 124-130.

[10] Edomwonyi, E.O., Nwokike, O.C. and Onuminya, J.E. (2014) Management of Traumatic Hip Dislocations in Irrua. International Journal of Science and Research, 3, 1904-1910.

[11] Meena, R.K., Singh, A.M., Singh, C.A., Chisti, S., Kumar, A.G. and Langshong, R. (2013) Pattern of Fractures and Dislocations in a Tertiary Hospital in North-East India. The Internet Journal of Epidemiology, 11, 1.

[12] Shaheen, M.A., Madr, A.A., Al-Kbudary, N, Kham, F.A., Mosalem, A. and Sabet, N. (1990) Pattern of Accidental Fractures and Dislocations in Saudi Arabia. Injury, 21, 347-350. http://dx.doi.org/10.1016/0020-1383(90)90115-B

[13] Akinyoola, A.L. and Abiodun, A.A. (2005) Bilateral Traumatic Anterior Hip Dislocation: A Case Report. West African Journal of Medicine, 24, 272-273.

[14] Meena, S., Barwar, N. and Chowdbury, B. (2014) Double Trouble: Testicular Dislocation Associated with Hip Dislocation. Journal of Emergencies, Trauma, and Shock, 7, 58-59. http://dx.doi.org/10.4103/0974-2700.125646

[15] Ebong, W.W. (1978) The Patttern of Fractures and Dislocations in Western Nigeria. Injury, 9, 221-224. http://dx.doi.org/10.1016/0020-1383(78)90012-8

[16] Alonge, T.O., Ogunlade, S.O. and Idowu, O.E. (2002) Traumatic Dislocation of the Hip Joint-Pattern and Management in a Tropical African Population. West African Journal of Medicine, 21, 288-290.

[17] Okaro, I.O. and Okadugha, C.O. (2006) The Anatomic Pattern of Fracture, and Dislocations among Accident Victims in Owerri. Nigerian Journal of Surgical Research, 8, 54-56.

[18] Bhaskara, K., Padmanabha, T.S. and Sindhu, N.T. (2014) Pattern of Fractures and Dislocations in a Tertiary Care Hospital, North-East Karnataka. International Journal of Medical Research \& Health Sciences, 3, 847-850.

[19] Jha, N., Srini, D.R., Roy, G. and Jagadish, S. (2003) Injury Pattern among RTA Cases: A Study from South India. Indian Journal of Community Medicine, 28, 85-90.

[20] Lima, L.C., Nascimento, R.A., Almeida, V.M.T. and Filho, F.A.M.F. (2014) Epidemiology of Traumatic Hip Dislocations in Patients Treated in Ceara, Brazil. Acta Ortopedica Brasileira, 22, 151-154.

[21] Kuhn, D. and Rosman, M. (1984) Traumatic, Nonparalytic Dislocation of Should in a Newborn Infant. Journal of Pediatric Orthopaedics, 4, 121-122

[22] Ugbeye, M.E., Alabi, E.O. and Dim, E.A. (2004) Fracture-Dislocation of the Shoulder Joint in a Child: A Case Report. African Journal of Trauma, 2, 94-95.

[23] Nicastro, J.F. and Adair, D.M. (1982) Fracture-Dislocation of the Shoulder in a 32 Month Old Child. Journal of Pediatric Orthopaedics, 2, 427-429.

[24] Madu, K.A., Lasebekhan, O.A., Eze, C.B. and Ezek, O. (2011) Traumatic Hip Dislocation, A South-East Nigeria Hos- 
pital Experience. Nigerian Journal of Orthopaedics and Trauma, 10, 13-15.

[25] Epstein, H.C. (1980) Traumatic Dislocations of the Hip. Williams and Wilkins, Baltimore.

[26] Gittins, M.E. and Serif, L.W. (1991) Bilateral Traumatic Anterior/Posterior Dislocations of the Hip Joints: Case Report. The Journal of Trauma, 31, 1689-1692. http://dx.doi.org/10.1097/00005373-199112000-00021

[27] Civil, I.D.S. and Tapsell, P.W. (1981) Simultaneous Anterior and Posterior Bilaterial Traumatic Dislocation of the Hips: A Case Report. Australian and New Zealand Journal of Surgery, 51, 542. http://dx.doi.org/10.1111/j.1445-2197.1981.tb05250.x

[28] Hil, R.J. and Chmell, S. (1990) Contalaterial Anterior/Posterior Traumatic Hip Dislocations. Orthopaedics, $13,87$.

[29] Sinha, S.N. (1985) Simultaneous Anterior and Posterior Dislocation of the Hip Joints. The Journal of Trauma, 25, 269270.

[30] Speed, K. (1953) Simultaneous Bilateral Traumatic Dislocation of the Hip. The American Journal of Surgery, 85, 292297. http://dx.doi.org/10.1016/0002-9610(53)90612-6

[31] Levin, P. (1992) Hip Dislocation. In: Browner, B.D., Jupiter, J.B., Levine, A.M. and Trafton, P.G., Eds., Skeletal Trauma, WB Saunders, Pliladephia, 1329-1367.

[32] Dreinhofer, E. and Immerman, E.W. (1967) Dislocation of the Hip Combined with Fracture of the Shaft of the Femur on the Same Side. Journal of Bone and Joint Surgery, 33A, 331-345.

[33] Helal, B. and Skevix, X. (1967) Unrecognized Dislocation of the Hip in Fractures of the Femoral Shaft. Journal of Bone and Joint Surgery, 49B, 293-300.

[34] Hunter, G.A. (1969) Posterior Dislocation and Fracture Dislocation of the Hip. A Review of Fifty-Seven Patients. Journal of Bone and Joint Surgery, 51B, 38 -44.

[35] Diabach, J.A. and Crockarell, J.R. (2003) Acute Dislocation. In: Canale, S.T., Daugherty, K. and Jones, L., Eds., Cambpell's Operative Orthopaedics, 10th Edition, Philadephia, 3167.

[36] Laorr, A., Green Span, A., Anderson, M.W., Moehring, H.D. and McKinley, T. (1995) Traumatic Hip Dislocation: Early MRI Finding. Skeletal Radiology, 24, 239-245. http://dx.doi.org/10.1007/BF00198406

[37] Rubel, I.F., Kloen, P., Potter Hollis, G. and Helfet David, L. (2002) MRI Assessment of the Posterior Acetabular Wall Fracture in a Traumatic Dislocation of the Hip in Children. Paediatric Radiology, 32, P435-P439.

[38] Cortes, V.C., Checa, L. and Vela, J.R. (1989) Reduction of Acute Anterior Dislocation of the Shoulder without Anaesthesia in the Position of Maximum Muscle Relaxation. International Orthopaedics, 13, 259-262. http://dx.doi.org/10.1007/BF00268508

[39] Poulsen, S.R. (1988) Reduction of Acute Shoulder Dislocations Using the Eskimo Technique: A Study of 23 Consecutive Cases. The Journal of Trauma, 28, 1382. http://dx.doi.org/10.1097/00005373-198809000-00013

[40] Thanni, L.O.A. (2000) Factors Influencing Patronage of Traditional Bone Selters. WAJM, 19, 220-224.

[41] Solagberu, B.A. (2005) Long Bone Fractures Treated by Traditional Bone Setters: A Study of Patient's Behaviour. Tropical Doctor, 35, 106-107. http://dx.doi.org/10.1258/0049475054036797

[42] Yamamoto, K.O.M., Masaoka, T., Shishido, T. and Imokire, A. (2004) Traumatic Anterior Dislocation of the Hip Associated with Ipsilateral Femoral Shaft Fracture in a Child: A Case Report. Journal of Orthopaedic Surgery (Hong Kong), 12, 126-132.

[43] Armstrung, J.R. (1948) Traumatic Dislocation of the Hip Joint. Journal of Bone and Joint Surgery, 30B, 430-445.

[44] Calkins, M.S., Zych, G., Latta, L., et al. (1988) CT Evaluation if Stability. Post Fracture-Dislocation of the Hip. Clinical Orthopaedics and Related Research, 227, 152-163

[45] Assmus, H. and Meinel, A. (1976) Schilterverletzung and Axillary Paresis. Hefte Unfallheiko, 76, 183-187. 